\title{
OS PROCESSOS DE POLÍTICAS PÚBLICAS E DE ACOLHIMENTO PARA HAITIANOS EM MARINGÁ-PR
}

Alex Sandro dos Santos ${ }^{1}$

RESUMO: O ano de 2010 marcou o início da imigração haitiana no Brasil. A entrada dos haitianos via Tabatinga, no Amazonas, começou a ser notada em fevereiro de 2010, logo após o terremoto, que sacudiu violentamente o Haiti, e em particular a capital, Porto Príncipe. O primeiro grupo de haitianos chegou à na cidade de Maringá, no Estado do Paraná em 2010, seguidos por outros fluxos migratórios internacionais. O objetivo da pesquisa é discutir a presença dos migrantes haitianos na região metropolitana de Maringá, seus desdobramentos e por fim mostrar atuação das políticas públicas e assistencialismo social local frente a este grupo. A metodologia adotada consistiu na pesquisa bibliográfica, histórica e na observação in loco do fenômeno, mormente, na cidade de Maringá PR. Por fim, o estudo procurou avaliar os principais aspectos da problemática, que é identificar quais as políticas públicas locais e ações de acolhimentos voltadas aos Haitianos. O resultado final da pesquisa demonstrou que há na cidade de Maringá, apenas ações não governamentais de acolhidas aos migrantes haitianos e que ação de punho político nas ações pública, ainda está em fase inicial de criação de projetos voltados para políticas públicas para esse grupo de migrantes na cidade.

Palavras-chaves: Migrantes; Haitianos; Maringá; Políticas públicas.

\section{PUBLIC POLICY AND WELCOME PROCESSES FOR HAITIANS IN MARINGÁ-PR}

\begin{abstract}
The year 2010 marked the beginning of Haitian immigration to Brazil. The entry of Haitians Tabatinga, in Amazonas, began to be noticed in February 2010, shortly after the earthquake, which violently shook Haiti, and in particular the capital, Port-au-Prince. The first group of Haitians arrived in the city of Maringa, in the State of Paraná in 2010, followed by other international migratory flows. The objective of the research is to discuss the presence of Haitian migrants in the metropolitan region of Maringa, its developments and, finally, to show the performance of public policies and local social assistance towards this group. The methodology adopted consisted of bibliographic, historical research and observation in loco of the phenomenon, mainly in the city of Maringa PR. Finally, the study sought to assess the main aspects of the problem, which is to identify which are the local public policies and welcoming actions aimed at Haitians. The final result of the research showed that in the city of Maringa, there are only non-governamental actions to welcome Haitian migrants and that political fist action in public actions is still in the initial phase of creating projects aimed at public policies for this group of migrants in the city
\end{abstract}

\footnotetext{
${ }^{1}$ Mestrando em Ciências Sociais pela UEM- Universidade Estadual de Maringá, Professor da Educação básica do estado do Paraná e rede privada. E-mail: alexsoldy@hotmail.com 
Keywords: Migrants; Haitians; Maringá; Public policy.

\section{INTRODUÇÃO}

O presente artigo tendo como unidade de análise os atuais fluxos migratórios de haitianos para o Brasil, empenhou em investigar os processos de políticas públicas e de acolhimentos á haitianos a cidade de Maringá Estado do Paraná. Essa população de haitianos, na cidade de Maringá, foi aumentando progressivamente, segundo dados fornecidos pela Entidade ${ }^{2}$ Aras Caritas localizada na cidade Maringá, que presta assistências sociais a imigrantes, em 2014 estimou-se um número superior de 4.000 indivíduos haitianos na região metropolitana de Maringá. A Mesma fonte estima-se que atualmente vivem na cidade de Maringá cerca de 1.900 Haitianos. Verificou com a pesquisa que os migrantes haitianos, que vivem na cidade, constituem um exército de reserva para regular o salário, a mobilização entre os trabalhadores e estão móveis e sujeitadas as forças do capital e que ainda não existe de fato uma política pública estabelecida pelo governo local, que atenta essa população.

As políticas públicas são uma resposta do Estado às necessidades do coletivo que, por meio do desenvolvimento de ações e programas, objetivam o bem-comum e a diminuição da desigualdade social. Segundo Leonardo Secchl, (2010), em seu livro "Políticas Públicas: conceitos, esquemas de análise, casos práticos", para estabelecer uma política pública, deve ser estruturado um ciclo de políticas que são as fases de maneira funcional e sequencial, para tomar possível a produção e organização do projeto. O capitulo três do livro Políticas Públicas, descreve como sendo o ciclo de políticas públicas os seguintes: identificação do problema, formação da agenda, formulação de alternativas, tomada de decisão, implementação avaliação e extinção.

A questão das políticas pública no Brasil, mediante os tantos problemas encontrado em sentido nacional, vem sendo gratuitamente melhorando seus conceitos e suas implementações. Desse modo, Celina Souza (2006) afirma que, nas últimas décadas, se registrou o ressurgimento da importância do campo de conhecimento,

\footnotetext{
${ }^{2}$ Aras- Caritas (Associação de Reflexão e Ação Social), constituída em 06 de fevereiro de 2006, é uma organização não governamental e sem fins lucrativos, com sede na cidade de Maringá, Estado do Paraná, situada à Rua Vereador Joaquim Pereira de Castro, 267 na Vila Santo Antônio. 
denominado políticas públicas e das instituições, regras e modelos que regem sua decisão, elaboração, implementação e avaliação.

Diante disso, verificou na pesquisa que na cidade de Maringá a implantação de políticas pública para população haitiana que vivem na cidade, está dentro do ciclo na fase de formação de agenda, que conjunto de problemas ou temas que a comunidade política perceba como merecedor de intervenção pública, ou seja, é aquela que elenca os problemas ou temas que o poder público já decidiu enfrentar. A fase dessa implementação ainda está sendo constituídas por reuniões e formações de setores interessados ou convidados pelos órgãos competentes na criação de ações que levarão a políticas públicas na cidade e região.

\section{CONTEXTUALIZAÇÃO HISTÓRICA}

O passado do país Haiti, mais pobre da América, segundo relatório de 2010 da United Nations Conferenceon Trade and Development - Unctad $^{3}$, e está entre os 49 mais pobres do mundo e é marcado pela violência, desigualdade social e instabilidade política desde o início de sua formação. A princípio, a ex-colônia francesa enfrentou treze anos de lutas sangrentas para conseguir sua independência em 1804, tornando-se a primeira república negra do mundo.

As consequências do terremoto que atingiu, esse país já tão estigmado no dia 12 de janeiro de 2010 revelam, mais do que a falência do Estado daquele país, mas também o fracasso de organizações que lutavam pela sua reconstrução, seja econômica ou de desigualdades.

A chegada de um grupo de haitianos no Brasil (Tabatinga-AM), dias após o terremoto, causou surpresa a todos, pois, ainda a presença desses imigrantes em solos brasileiros era algo novo se e à medida que tal fluxo foi aumentando nas fronteiras brasileiras essa surpresa deu lugar a tamanho despreparo em caráter de acolhida e num curto espaço de tempo, esses imigrantes se encontravam em todos os estados do Norte e

\footnotetext{
${ }^{3}$ A Conferência das Nações Unidas sobre Comércio e Desenvolvimento foi estabelecida em 1964, em Genebra, Suíça, no contexto das discussões de liberalização do comércio no Acordo Geral de Tarifas e Comércio. 
Centro-Sul do Brasil, ou pelo menos por ali passaram, inserindo-se em diferentes atividades do mercado de trabalho.

A presença de Haitianos no Brasil era quantitativamente inexpressiva até 2010, como demonstra registros do IBGE. 2015.

\begin{tabular}{|l|l|}
\hline 1940 & 16 Haitianos \\
\hline 1950 & 21 Haitianos \\
\hline 1970 & 90 Haitianos \\
\hline 2000 & 15 Haitianos \\
\hline 2009 & 36 Haitianos \\
\hline 2014 & 21.430 Haitianos \\
\hline
\end{tabular}

Fonte: IBGE 2015- Haitianos no Brasil.

$\mathrm{Na}$ tentativa de intensificar e identificar operfil dessa imigração haitiana, diferentes bases de dados já foram construídas e analisadas, entre elas, a dos registros da Polícia Federal sobre a entrada de estrangeiros no Brasil (Sistema Nacional de Cadastro e Registro de Estrangeiros - Sincre/PF), produzida por Duval Fernandes e Andressa Virgínia deFaria( 2016). Tais dados apontam para uma população com idade média de 31,7 anos, sendo que a maioria $(70 \%)$ se concentra entre as faixas etárias de 25 a 39 anos. Com relação ao sexo, verifica-se que os homens ainda constituem o maior contingente, embora a proporção de mulheres venha aumentando nos últimos anos, chegando a $40 \%$ em 2015, fato que pode indicar um processo de reunificação das famílias que lá no Haiti haviam ficado (Fernandes, Faria, 2016, p. 106).

Não importa se a migração é em grande proporção ou não, o certo é que a mesma ocorre a todo tempo. Cada um dos indivíduos tem sua história, e acabam por deixar seu paíspor possui uma motivação.

\section{A LEI 9474/97 DE PESSOA REFUGIADA E AS POLÍTICAS DE PROTEÇÃO}


A Lei $9474 / 97^{4}$ é a lei que no Brasil define o conceito de pessoa refugiada e as políticas de proteção e acolhimento às pessoas refugiadas e solicitantes de refúgio. $\mathrm{O}$ Estatuto dos refugiados é o nome que se estabeleceu dar à Convenção de 1951, da qual o Brasil foi signatário. Todo refugiado tem direito à proteção internacional e os Estados têm o dever jurídico de respeitar a Convenção sobre o Estatuto dos Refugiados de 1951, sendo que muitos dos direitos relevantes à proteção dos refugiados são direitos fundamentais assegurados pela Declaração Universal (PIOVESAN, 2015, p. 132).

Já o asilo é aplicado em casos de perseguição política. Importante destacar que o asilo é constituído por um ato soberano do Estado, não se sujeitando a nenhum organismo internacional. O refúgio, ao contrário, não se reveste de cunho político, é de forma geral e internacional visto o seu caráter universal, que visa o auxílio às pessoas vítimas de violações em seus direitos humanos fundamentais, que permite o termo de refugiados.

Antes de contar com uma lei própria, os pedidos de refúgio no Brasil eram julgados de acordo com os termos da Convenção e o conceito de refugiado ampliado pelo Protocolo de 1967.O Brasil tem um misto de migrações, recebendo diferentes migrantes: econômicos, em situação de necessidade humanitária, refugiados, apátridas, indocumentados, enfim, categorias específicas que necessitam de políticas específicas e por isso que instituir uma lei que visa tratar desses assuntos é de suma importância. A lei brasileira define que também é refugiada a pessoa que deixou seu país em razão de grave e generalizada violação de direitos humanos (Declaração de Cartagena, 1984).

O Estatutoeditado pela lei no 9474, de 1997, com 49 artigos traz para o conceito e tema sobre os refugiados, uma característica, mas familiar, trata para os refugiados sua condição jurídica, os procedimentos para o pedido de refúgio, lembrando que a situação irregular, conforme exposto na lei em seu artigo $8^{\circ}$, não constitui impedimento para o pedido; cessação da situação de refugiado, expulsão e repatriação.

\section{NOVA LEI DE MIGRAÇÃO NO BRASIL}

\footnotetext{
${ }^{4}$ LEI N ${ }^{\circ}$ 9.474, DE 22 DE JULHO DE 1997. Define mecanismos para a implementação do Estatuto dos Refugiados de 1951, e determina outras providências. 
Texto substitui o Estatuto do Estrangeiro, criado em 1980, e trata o migrante sob a ótica dos direitos humanos. A lei é bastante inovadora e está em consonância com obrigações internacionais assumidas pelo Brasil. As principais mudanças e avanços que a nova lei traz são sobre proteção aos apátridas.Nenhuma outra norma anterior à Lei de Migração tratava da proteção aos apátridas, asilados e brasileiros no exterior, apenas tratados internacionais. A nova lei organiza a cooperação jurídica entre países para essa finalidade.

A nova lei determina a existência de um visto temporário específica para o migrante em situação de acolhida humanitária, para pessoas que precisam fugir dos países de origem, mas que não se enquadram na lei do refúgio. Migrantes com documentação inexistente ou irregular poderão regularizar a situação dentro do Brasil. O Estatuto do Estrangeiro proibia imigrantes de participarem de qualquer atividade de natureza política. A nova lei que foi publicada no Diário oficial em Brasília - DF, quinta-feira, 25 de maio de 2017, acaba com a proibição e garante o direito do imigrante de se associar a reuniões políticas e sindicatos.

Entre os desafios que migrantes e refugiados enfrentam no Brasil estão formas e situações em que as desigualdades de que são portadores se transformam em fatores de exclusão ou de discriminação. Para Charles Tilly (2006) as desigualdades se dão entre categorias sociais separadas por fronteiras onde acontece a interação dos sujeitos que pertencem a tais categorias. Sendo assim, o que temos é uma desigualdade categórica. Por desigualdade categórica entende-se que há formas de benefício desigual em que conjuntos inteiros de pessoas não recebem o mesmo tratamento.

Para Marta Arretche (1996), que em uma de suas obras, analisa todos os desdobramentos da desigualdade, seja ela social, de gênero ou de etnias descreve a desigualdade como sendo um "termo compreendido de forma plural". Marta Arretche (1996), "no mundo social, existem múltiplas assimetrias, seja entre pobres e ricos, entre mulheres e homens, entre as etnias, que se manifestam em diversos fatores da vida cotidiana como a renda, no acesso a serviços básicos e na participação política. Entender a desigualdade é examinar suas múltiplas dimensões”.

Certamente, a questão migratória no Brasil está ganhando mais espaço no debate público. No âmbito nacional, se discute um novo marco jurídico para a questão migratória, através da adoção de uma lei que substitua o atual Estatuto do Estrangeiro 
(criado durante a ditadura militar). É percebível que para uma melhor compreensão de todas essas desigualdades que envolvem esses indivíduos, encontra o Estado como centro primordial, para tais processos.

SegundoRobert Alan Dahl(2005), "O Estado deve garantir o direto de existência de tudo àquilo que podemos considerar como sendo associações que permitem uma melhoria na vida dos cidadãos". Ou seja, o Estado é potencializados de políticas públicas até mesmo no sentido de reduzir dificuldades de descriminação aos migrantes e não só de ações sociais.

Em 2014, foi realizada a $1^{\text {a }}$ Conferência Nacional sobre Migrações e Refúgio (Comigrar), reunindo migrantes, profissionais e estudiosos envolvidos na temática migratória, servidores públicos e representações nacionais e internacionais diversas, para uma reflexão coletiva e elaboração de aportes para a construção da Política e do Plano Nacionais de Migrações e Refúgio.

\section{DESTINO BRASIL}

O recente fluxo migratório de haitianos para o Brasil iniciou-se de forma tímida, após o tremor de 2010, porém intensificou-se no final de 2011 e começo de 2012. Estima-se que, neste período, cerca de 4.000 imigrantes haitianos, segundo dados do Ministério da Justiça - MJ, entraram ilegalmente no país. Os haitianos adentraram principalmente pelas fronteiras do Acre e do Amazonas, mas há rotas nos estados de Roraima, Mato Grosso e Amapá.

Simultaneamente, a toda essa crise no Haiti, havia um grande crescimento econômico, e em especial na região sul brasileira, em que a região metropolitana de Maringá, tem destaque nesse processo econômico e torna se um polo de atração. Faltava mão de obra na indústria da construção civil e na indústria agropecuária, como os frigoríficos da região e a solução foi trazer essa mão de obra para a região, eram os haitianos que foram recrutados no Acre ou em São Paulo.Subjetivamente concluí que a migração ainda tem o mesmo papel que tinha no período do império ${ }^{5}$ que era de

\footnotetext{
${ }^{5}$ O Império do Brasil foi um Estado que existiu no século XIX e que compreendia, aproximadamente, o território que forma o Brasil e o Uruguai atuais. Seu governo era uma monarquia constitucionalparlamentarrepresentativa, tendo tido como imperadores D. Pedro Ie seu filho, D. Pedro II. 
resolver o problema da falta de mão de obra escravista e não capacitados de direitos algum. Toda essa problemática aumenta, quando o imigrante não é acolhido com políticas públicas que os capacita de direitos. Tais políticas ainda é tabu para maioria da sociedade é um tema que ainda causa estranheza por parte de muitos cidadãos. Segundo o site Band.com, em matéria apresentada em abril de 2012, os haitianos que chegam ao Paraná também recebem ajuda de Pastorais, devido à falta de políticas do Estado. As entidades ligadas à Igreja Católica eram as que prestava uma ajuda imediata aos migrantes, como a doação de roupas, alimentos e também ajudam a encontrar um lugar para ficar.Os haitianos buscavam no início da imigração, empregos em fábricas e usinas, e eram considerados uma mão de obra qualificada por aprenderem rapidamente suas tarefas. Hoje encontramos haitianos em diversos estados brasileiros, mas principalmente no sul e centro oeste do país. A maioria vem para o Brasil e deixa suas famílias para trás.

\section{OS HAITIANOS NA CIDADE DE MARINGÁ}

Segundo a Policia Federal, o núcleo de migração na região de Maringá, os Haitianos são a maioria. Até o primeiro semestre de 2018 estavam registrados cerca de 5.562 haitianos na região de Maringá e no início do ano de 2019, foram regularizados mais 824 haitianos na cidade e região e que dos imigrantes haitianos residentes em Maringá, $72 \%$ é do sexo masculino, e $28 \%$ do sexo feminino e em relação à faixa etária todos estão em idade ativa. As mulheres apresentam uma média de idade mais jovem que os homens, e aproximadamente $50 \%$ estão entre 18 e 29 anos, onde desses cerca de $69 \%$ são solteiros e $28 \%$ casados, e os restantes estão entre viúvos (1\%) e divorciados $(2 \%)$.

Para migrar juntaram todas as suas economias e passaram por uma diversidade de obstáculos para realizar esse percurso e chegar ao Brasil, e em especial em Maringá. Encontramos esses imigrantes haitianos na rotina maringaense. Estão trabalhando nos restaurantes da cidade, nas ruas como camelos, em indústrias e até mesmo no campo.

No dia (14) de junho de 2014, aconteceu na Prefeitura de Maringá a criação do Comitê do Migrante que tem como objetivo principal a elaboração de propostas para compor o plano municipal de políticas públicas. Comitê formado com a articulação feita 
pelas ARAS, pelo Vereador Carlos Mariucci e pela Associação de Moradores Vila Santo Antônio, levando as demandas que já são trabalhadas nas entidades para o Município.

Sobre números de haitianos em Maringá, é muito difícil definir, pois a vulnerabilidade é muito grande.(Não tem emprego em Maringá, eles vão para Londrina, Curitiba) e essas saídas não são comunicadas a polícia federal, ou seja, não tem como contabilizar $100 \%$. Assim sendo a entidade trabalha com estimativas. E segundo essa estimativa há hoje cerca de 1.900 haitianos em Maringá.

\section{AÇÕES DE POLÍTICAS PÚBLICAS AOS HAITIANOS EM MARINGÁ}

Pela primeira vez o município de Maringá, inclui os estrangeiros na pauta administrativa. O Prefeito em exercício Ulisses Maia deu total autonomia ao comitê com a garantia de verbas para implementação dos projetos.

Foi Criado um Comitê do Migrante da Cidade de Maringá em 14/06/2017, para a elaboração de propostas para compor o plano municipal de políticas públicas. O comitê está disponibilizado seu decreton ${ }^{\circ} .743 / 2017$, no site da Prefeitura Municipal de Maringá. O comitê é composto por entidades governamentais e não governamentais e por algumas secretarias, tais como - SEPLAN - Secretaria de Planejamento e Urbanismo; SASC - Secretaria de Assistência Social e Cidadania; SEMUC - Secretaria Municipal de Cultura, SEDUC - Secretaria Municipal de Educação; SESP - Secretaria Municipal de Esporte e Lazer; SEMA - Secretaria Municipal de Meio Ambiente e Bemestar Animal; SEMULHER Sec. Municipal da Mulher, Igualdade Racial, Juventude e Pessoa Idosa, SAUDE - Secretaria Municipal de Saúde; UEM - Universidade Estadual de Maringá; NRE - Núcleo Regional de Educação.

Os membros das entidades não governamentais são compostos por ARAS Caritas, Associação Haitiana em Maringá; Associação Comunitária da Vila Santo Antônio; OPEM - Ordem de Pastores Evangélicos de Maringá; associação Comunitária da Vila Esperança; Comissão dos Estrangeiros e Migrantes da OAB - Ordem dos Advogados do Brasil. Entre as atribuições do comitê está a formação de grupos de trabalho para formulação de propostas de políticas públicas, elaboração do plano 
municipal com diretrizes, metas, objetivos, instrumentos e ações governamentais, considerando a preservação da história, memória e influência cultural dos migrantes.

O comitê também tem como papel se articular com órgãos e instituições encarregadas para proteção e defesas de direitos humanos, ampliando as informações e serviços voltados aos migrantes, formulando estudos e pesquisas para identificação de demandas. O Prefeito Ulisses Maia destacou o dia da criação do comitê de políticas públicas para migrantes haitianos como "histórico" e ressaltou que a administração irá construir junto com a comunidade as políticas públicas para os migrantes:

\footnotetext{
"Não temos apenas acolher os migrantes, mas garantir de forma plena seus direitos. Toda essa qualidade da saúde e educação deve ser prestada também a essas pessoas. Queremos humanizar Maringá. Lembro-me de meu pai que era grego e veio ao Brasil, no final dos anos 40, e penso na dificuldade que os migrantes passam. A partir de hoje, vocês que vieram de outros países podem se considerar cidadãos maringaenses", afirmou o prefeito (2017).
}

O haitiano Fritzner Saint Cloris, 27 anos, da cidade de Gonaïves, uma das maiores do país, está em Maringá há quatro anos, e disse estar "muito feliz" pela criação do comitê:

\footnotetext{
"Viemos para o Brasil para ter uma vida melhor e não para passar dificuldade e sofrer. Somos de um país pobre, mas isso não significa que não temos uma cultura rica. O imigrante não quer fazer mal, a maioria dos que vêm aqui é para fazer o bem. Queremos crescer juntos com os maringaenses", afirmou o Haitiano (2017).
}

Também a Prefeitura Municipal da cidade de Maringá, disponibiliza via site, http://www2.maringa.pr.gov.br/site/, um guia de Informações e Contatos para Migrantes, Refugiados e Apátridas, onde é descrito alguns endereços de assistências locais.Criação da Associação de Haitianos em Maringá - PR e estudo sobre criação da "Casa de Passagem" para os haitianos. Nessa casa de passagem, os haitianos recémchegado na cidade terá acolhimento e encaminhamento a entrevistas de empregos. A casa registrará o acompanhamento dos migrantes até o mesmo conseguir moradia e emprego. 


\section{AÇÕESDE ACOLHIDAS AOS HAITIANOS NA CIDADE DEMARINGÁ ATRAVÉS DA ENTIDADE ARAS CARITAS}

Aras - Caritas (Associação de Reflexão e Ação Social), constituída em 06 de fevereiro de 2006, é uma organização não governamental e sem fins lucrativos, com sede na cidade de Maringá, Estado do Paraná, situada Rua Vereador Joaquim Pereira de Castro, 267 na Vila Santo Antônio. Com o título de Utilidade Pública Municipal na forma da Lei no 7849/07 e membro da Rede Caritas Brasileira, possui atuação em todo o território nacional, entretanto desenvolve seus principais projetos na Região Metropolitana e Arquidiocesana de Maringá.

ARAS - CaritasMaringá fez as suas primeiras inserções com os migrantes que se estabeleciam na região. $\mathrm{O}$ objetivo era estabelecer um maior diálogo, desdobrando em um melhor acolhimento dos migrantes no Norte-Central do Paraná. Desse modo a entidade começou a acompanhar os trabalhos dos solicitantes de visto de permanência e no diálogo percebia e identificava as possibilidade e limites do órgão responsável pela regularização e pedido de refúgio, em Maringá.

As ações de acolhimento aos Haitianos na cidade, conduzidas pela Associação Aras, são várias e de estilos diferentes. Entre elas destacaram, o cadastramento e atendimento humanitário aos haitianos (ponte entre haitianos e polícia federal), a distribuição de cestas básicas, curso de língua portuguesa, com a colaboração de professores voluntários com a consultoria de professores da UEM, e regularização de passaportes, ou vistos de permanência e outros documentos. A Associação, sempre teve o intuito de ser um órgão informativo aos haitianos e ações voltadas para auxilio em quesitos sobre sociedade, cultura e ações sociais entre elas, palestras sobre questões trabalhistas, reprodução de cartilhas sobre questões trabalhistas, disponibilização de um advogado voluntário de plantão todas as terças-feiras de manhã para atendimento aos migrantes nas questões trabalhistas, auxiliando juridicamente esse grupo em situação de vulnerabilidade, atividades culturais (Dia das Mães, Páscoa), condução de situações tristes como a organização de velório, enterro e almoço de confraternização no Natal. Todas essas ações são realizadas por recursos próprios, oriundos de ajudas individualizadas e parcerias com a sociedade civil. 


\section{CONSIDERAÇÕES FINAIS}

$\mathrm{O}$ artigo discutiu a presença dos migrantes haitianos na região metropolitana de Maringá, apurando que, em seus desdobramentos, verificam-se até o atual cenário, apenas ações de acolhidas por órgãos não governamentais para os migrantes haitianos. $\mathrm{Na}$ ausência de uma política consolidada por parte do Estado, a sociedade civil busca a sua organização, ora desarticulada e ora coordenada, que atentam de forma satisfatória as necessidades desses indivíduos, que estão na cidade de Maringá, na esperança de um futuro melhor.

Verificou no contexto de acolhidas aos haitianos, ações da entidade Aras Caritas Maringá e outra série de ações vistas pelos voluntariados, de diversas origens e religiões, todas as ações individuais. O Estado começa a dar passos lentos em relação ao acolhimento, por meio de criação de comitê para implantação de políticas públicas aos haitianos, mas muito aquém das necessidades emergenciais que os haitianos se encontram em Maringá.

Como resultado final na presente pesquisa, foi observado, algumas ações que foram e estão sendo realizadas para amparar esta população, porém, aquém das necessidades destes migrantes. É percebível uma desarticulação tanto dos agentes sociais e da governança no acolhimento destes migrantes, ficando esta função com maiores efetividades para organizações independentes de políticas públicas.

\section{REFERÊNCIAS BIBLIOGRÁFICAS}

ARRETCHE, Marta TS. Emergência e desenvolvimento do Welfare State: teorias explicativas. Boletim Informativo e Bibliográfico em Ciências Sociais, v. 39, p. 3-40, 1995.

DAHL, Robert A. Poliarquia. 1. reimpr. São Paulo: Editora da Universidade de São Paulo, 2005.

DE Moraes, Isaias Albertin, Carlos Alberto Alencar de Andrade, and Beatriz Rodrigues Bessa Mattos. A imigração haitiana para o Brasil: causas e desafios. Conjuntura austral 4.20 (2013): 95-114.

FERNANDES, Duval; FARIA, Andressa Virgínia de. A diáspora haitiana no Brasil: processo de entrada, características e perfil. Imigração haitiana no Brasil. Jundiaí: Paco Editorial, p. 95-111, 2016. 
GOFFMAN, Erving. Estigma: notas sobre a manipulação da identidade manipulada. Rio de Janeiro: LTC, 2013.

http://aras.org.br/?cod=pagina/caritas-maringaacute/257 (Acesso em 12/11/2019).

http://www.ibge.gov.br/home/ (Acesso em 09/12/2019).

http://www2.maringa.pr.gov.br/site/ (Acesso em 11/02/2020).

SECCHI, Leonardo. Introdução: percebendo as políticas públicas. Políticas Públicas: conceito, esquemas de análise, casos práticos. São Paulo: Cengage Learning, 2010.

SOUZA, Celina. Políticas públicas: uma revisão da literatura. Sociologias, n. 16, p. 20-45, 2006. 